\title{
Absence of Responses to Microstimulation at the Hand-Face Border in Baboon Primary Motor Cortex
}

\author{
Donald D. Samulack, Robert S. Waters, Robert W. Dykes and Patricia A. McKinley
}

\begin{abstract}
Intracortical microstimulation (ICMS) was used to map the primary motor cortex of four adult female baboons, anesthetized with a mixture of halothane and nitrous oxide and supplemented with sodium pentobarbital. The sequence of observed muscle contractions in response to ICMS provided evidence of an orderly mototopic representation of the tongue, face, hand, forearm and upper body. A zone of cortex unresponsive to microstimulation was consistently observed at the border between the face and hand representation of the mototopic map. This zone was observed in all four animals and was consistent over time. Repeated confirmations of the unresponsive nature of these regions were obtained both early and late in the same experiment. No motor-unit responses or muscle contractions were detected by electromyographic (EMG) recording during stimulation of the unresponsive zones. The absence of both visually observed and EMG-recorded contractions and the fact that muscle contractions could be elicited from adjacent regions of cortex with ICMS as low as 1-5 $\mu \mathrm{A}$ provide compelling evidence that the finding reflects a true physiological condition rather than an experimental artifact.
\end{abstract}

RÉSUMÉ: Absence de réponse à la microstimulation au niveau de la jonction main-face dans le cortex moteur primaire chez le baboin La microstimulation intracorticale (MSIC) a été utilisée pour cartographier le cortex moteur primaire de quatre baboins femelles adultes, anesthésiées avec un mélange d'halothane et d'oxyde nitreux supplémenté par du pentobarbital sodique. La séquence des contractions musculaires observées en réponse à la MSIC a mis en évidence une représentation mototopique ordonnée de la langue, de la face, de la main, de l'avant-bras et du haut du tronc. Une zone du cortex qui ne répondait pas à la microstimulation était observée de façon constante à la jonction entre la représentation de la face et celle de la main sur la carte mototopique. Cette zone a été observée chez les quatre animaux et elle était présente de façon constante dans le temps. La confirmation répétée de la non-réponse de ces régions a été obtenue tant au début qu'à la fin de la même expérience. Aucune réponse au niveau des unités motrices et aucune contraction musculaire n'a été détectée par électromyographie (EMG) pendant la stimulation des zones de non-réponse. L'absence de contraction visible ou enregistrable à l'EMG et la fait que des contractions musculaires pouvaient être déclenchées dans des régions adjacentes du cortex avec une MSIC aussi faible que 1-5 $\mu \mathrm{A}$ sont une indication indiscutable que ces observations reflètent une condition physiologique réelle plutôt qu'un artéfact.

Can. J. Neurol. Sci. 1990; 17.24-29

Early clinical observations of focal epileptic seizures and electrical stimulation studies of Fritsch and Hitzig ${ }^{1}$ provided the first convincing evidence that frontal cortex plays a role in motor control. Subsequent studies near the turn of the century and in the early 1900s employing surface electrical stimulation, strychninization and ablation documented that the primary motor cortex was localized on the precentral gyrus. The focus of interest in the first half of this century was on the representation of muscles and movements in the precentral cortex, and by the 1950s a large number of different species had been mapped using surface electrical stimulation. ${ }^{2}$

With the introduction of intracortical microstimulation (ICMS) technique, ${ }^{3}$ it became possible to study the details of motor organization using stimulating currents several hundred times weaker than current levels used in surface stimulation. The use of stimulating currents as low as $10 \mu \mathrm{A}$ made it possible to activate a small volume of cortex containing only a few large pyramidal tract neurons and elicit contractions of single or small groups of muscles. ${ }^{4,5}$

The ICMS technique has provided considerable information concerning the representation of muscles in the motor cortex of several species of primates ${ }^{6-14}$ and subprimates. ${ }^{15,16}$ Several hypotheses about the organization of motor cortex have been derived from motor map data. Whereas previous hypotheses have emphasized the contiguous nature of motor cortex representation, our data showing clear unresponsive zones provide

From the Department of Physiology, McGill University, Montreal (D.D.S., R.W.D.); Department of Anatomy and Neurobiology, The University of Tennessee, Memphis (R.S.W.); Department of Physical and Occupational Therapy, McGill University, Montreal (P.A.M.)

Received June 9, 1989. Accepted in final form October 23, 1989

Reprint requests to: Robert S. Waters, Department of Anatomy and Neurobiology, The University of Tennessee, Memphis, 875 Monroe Avenue, Memphis, Tennessee, U.S.A. 38163 
evidence of a noncontiguous organization in a higher order nonhuman primate.

\section{METHODS}

Four female adult baboons (Papio h. anubis $10-13 \mathrm{~kg}$ ) were studied. Each animal was tranquilized with an intramuscular (IM) injection of ketamine hydrochloride $5.25 \mathrm{mg} / \mathrm{kg}$ and xylazine $0.45 \mathrm{mg} / \mathrm{kg}$. The hair on the head, neck, shoulders and arms was shaved to facilitate visual identification of fine muscle twitches. A tracheotomy was performed, a tracheal tube was inserted and the anesthesia was gradually altered to a gaseous mixture containing approximately $1 \%$ halothane, $40 \%$ nitrous oxide and $59 \%$ oxygen. Penicillin $(11,000 \mathrm{IU} / \mathrm{kg} / \mathrm{day}$ of procaine and benzathine penicillin-G; IM) and netilmicin sulfate (50 mg twice daily; IM) were administered as prophylactic antibiotic agents. A venous catheter was inserted in the saphenous vein and a $5 \%$ Dextrose (in $0.45 \%$ saline) supplemented with potassium was infused through the vein to compensate for fluid loss. Physiological parameters (blood pressure, heart rate, temperature, electrolytes and blood gases) were monitored throughout the surgical and experimental periods, and corrective steps were taken to adjust deviations from normal values.

The animal was placed in the prone position, its head fixed in a stereotaxic apparatus, and craniotomy exposing most of the somatosensory and motor gyri was performed. Movements of the brain induced by the heart beat were dampened by opening the cisterna magna. A well of dental impression compound was formed around the craniotomy and filled with Elliott's solution (Abbott). The dura over the lateral portion of the precentral gyrus was reflected, and the cortical surface was covered immediately with a thick layer $(2-3 \mathrm{~cm})$ of warmed silicon $(10,000 \mathrm{cs})$ fluid that provided a thermal insulated barrier. The silicon fluid was replaced with warm fluid every few hours. A head holder, consisting of a metal rod fixed to the recording table and anchored to the skull with stainless steel screws and dental acrylic, replaced the stereotaxic apparatus during recording. This head-holding device permitted an unobstructed view of the head, neck, throat and tongue regions, as well as the forelimb and shoulder. The level of gaseous anesthesia was thereafter reduced, and areflexia was controlled at threshold levels by regular intravenous injections of sodium pentobarbital (approximately $1 \mathrm{mg} / \mathrm{kg} / \mathrm{hr}$, or as necessary). ICMS was delivered while blood pressure, electrocardiogram (EKG) and respiration were continuously monitored. In no case did we observe that ICMS either enhanced the heart rate and respiration or altered the blood pressure. These results suggest that the animals suffered no discomfort or arousal during the experiment. Each experiment was a single continuous session, lasting $53-81$ hours.

Custom-fabricated tungsten-in-glass microelectrodes $(0.7$ $0.8 \mathrm{M} \Omega)^{4}$ controlled by a Narashige micromanipulator passed trains of $12-13$ cathodal stimulating pulses $(0.2 \mathrm{~ms}$ duration, $300 \mathrm{~Hz}$ ) from a stimulus isolation unit. ${ }^{17}$ The intensity of the stimulation current was measured by the voltage drop across a $10-\mathrm{K} \Omega$ resistor and was monitored on the oscilloscope. Visual observation and/or electromyographic (EMG) recording from Teflon-coated silver wires were used to detect muscle activation. EMG electrodes recorded primarily multi-unit responses, although single isolated motor unit responses were sampled. On insertion of the microelectrode into the cortex, a $30-\mu \mathrm{A}$ current was used to probe for motor responses. If a motor response was observed, the current was lowered until the observed contraction or motor unit response disappeared. The current was then increased until the response reappeared (defined as threshold). Likewise, if no motor response was observed using the search stimulus, the current was raised in $10-\mu \mathrm{A}$ increments until the threshold was determined or until a maximum level of $80 \mu \mathrm{A}$ was reached. The cortex was sampled in this manner at $200-\mu \mathrm{m}$ steps along each of the penetrations, and descriptions of the movement, the responsible muscle, and the threshold current were recorded at each effective site.

These data were summarized in two dimensions by indicating the location of each electrode penetration on a photograph of the cortical surface and then coding the penetration sites according to the motor response elicited. More detail was obtained by transposing the location of each penetration to planar coordinates in a computer and then entering the data from each stimulating site in each penetration as the third axis of a three-dimensional data set.

At the end of the experiment, electrolytic lesions were made by passing anodal current of $10 \mu \mathrm{A}$ for $10-20 \mathrm{~s}$. The animals were perfused with $0.9 \%$ saline and $10 \%$ buffered formalin, and the brains were removed. The region containing the central sulcus was blocked and prepared for sectioning. Serial frozen sections were cut from the first brain at $80-\mu \mathrm{m}$ thickness and stained with thionin. The other brains were embedded in celloidin and sectioned at either 80 or $120 \mu \mathrm{m}$ and stained with methylene blue, chloride. The sections were then examined using the light microscope, and sections were reconstructed using a camera lucida drawing system.

\section{Results}

A total of 10,052 sites were tested in the four animals. Of these sites, $6,186(61.5 \%)$ were stimulated in grey matter and $1,849(30 \%)$ were activated with $40 \mu \mathrm{A}$ or less. Of the effective sites, $28 \%$ were activated with stimulation currents of less than $10 \mu \mathrm{A}$. Motor responses were activated, for the most part, on the anterior wall of the central sulcus. The representation of body parts encountered in the cortex began laterally with the muscles of the tongue. The representation of the face overlapped the medial border of the tongue representation and extended medially, followed by the hand, forearm and shoulder representations in a medial progression. Although this order was consistent from animal to animal, the cortical area devoted to any one of these major muscle groups varied among animals both in size and in general orientation (see Figure 1).

A second important observation is apparent in Figure 1. Within the cortex of the precentral gyrus, many penetrations failed to encounter sites where muscle contractions could be elicited, even though they traversed 8 to $10 \mathrm{~mm}$ of cortex along the wall of the central sulcus. Not only did unresponsive areas surround the motor map but a large unresponsive zone was also found consistently between the hand and face representations. The unresponsive cortex located between the face and hand representations is designated in Figure 1 by a bar and an asterisk. This unresponsive region was particularly well studied in the third animal.

All electrode penetrations were reconstructed from serial sections. Those stimulus sites shown to lie in white matter were 

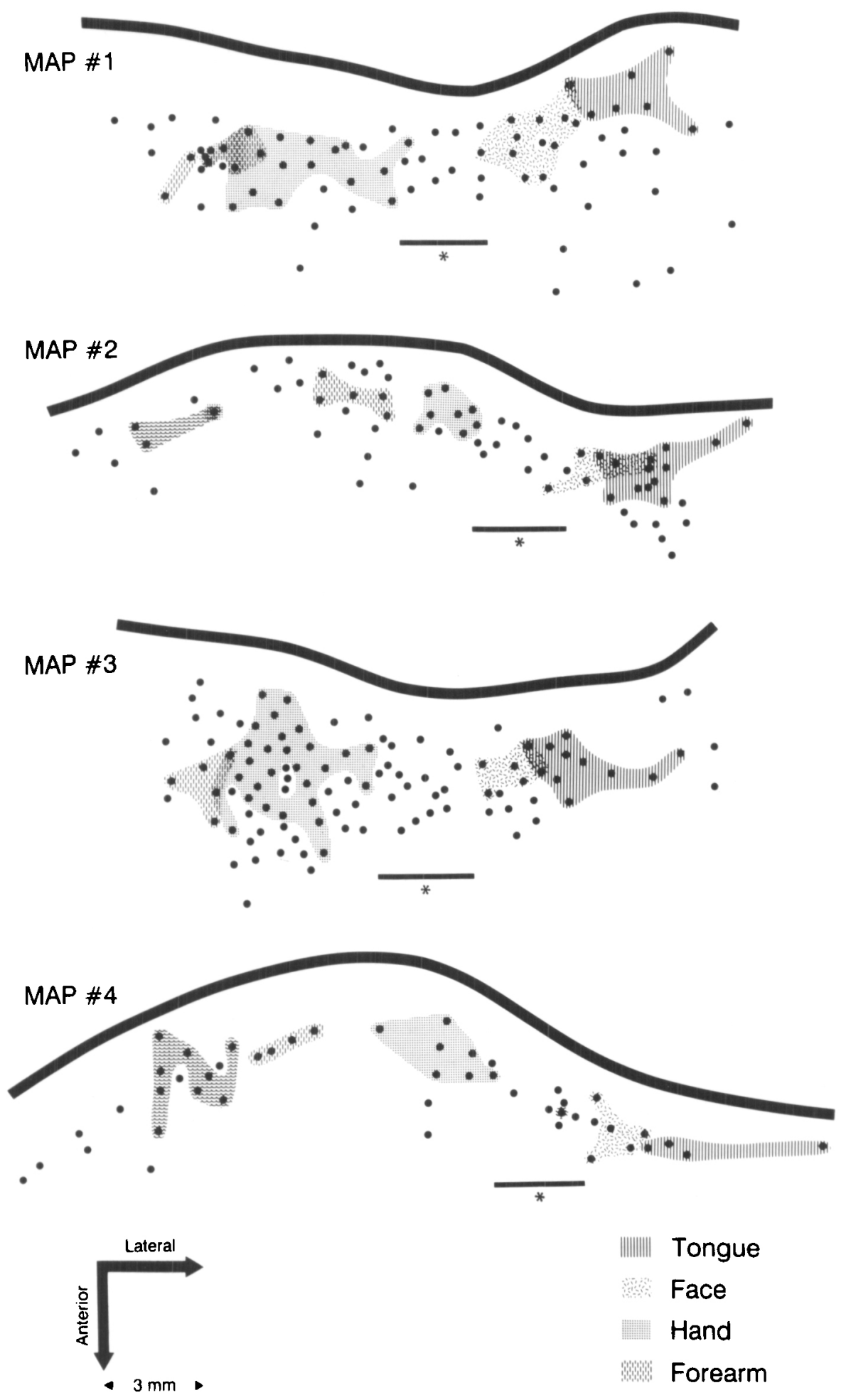

Tongue

Face

Hand

Forearm

\section{Shoulder}

Figure I - Reconstruction of the electrode entry sites on the cortical surface of the precentral gyrus in four baboons. Each site has been classified on the basis of the body part which was best represented throughout the grey matter of that penetration. Non-shaded entry sites represent those penetrations where no movements were observed. The generalized mototopic progression within the cortex is such that tongue is represented most laterally, followed in a medial direction by representation of the muscles of the face, hand, forearm and shoulder. The data indicate that a region of cortex (approximated by a straight bar and asterisk) at the transition zone from face to hand in the mototopic map does not elicit muscle contraction in response to microstimulation. This zone of unresponsiveness is comparable in size between animals. In cortical map \#4, the first penetration of the experiment detected several sites located between the hand and face representation that elicited movements of muscles within the shoulder: Subsequent penetration in and around the same location failed to confirm this observation. 

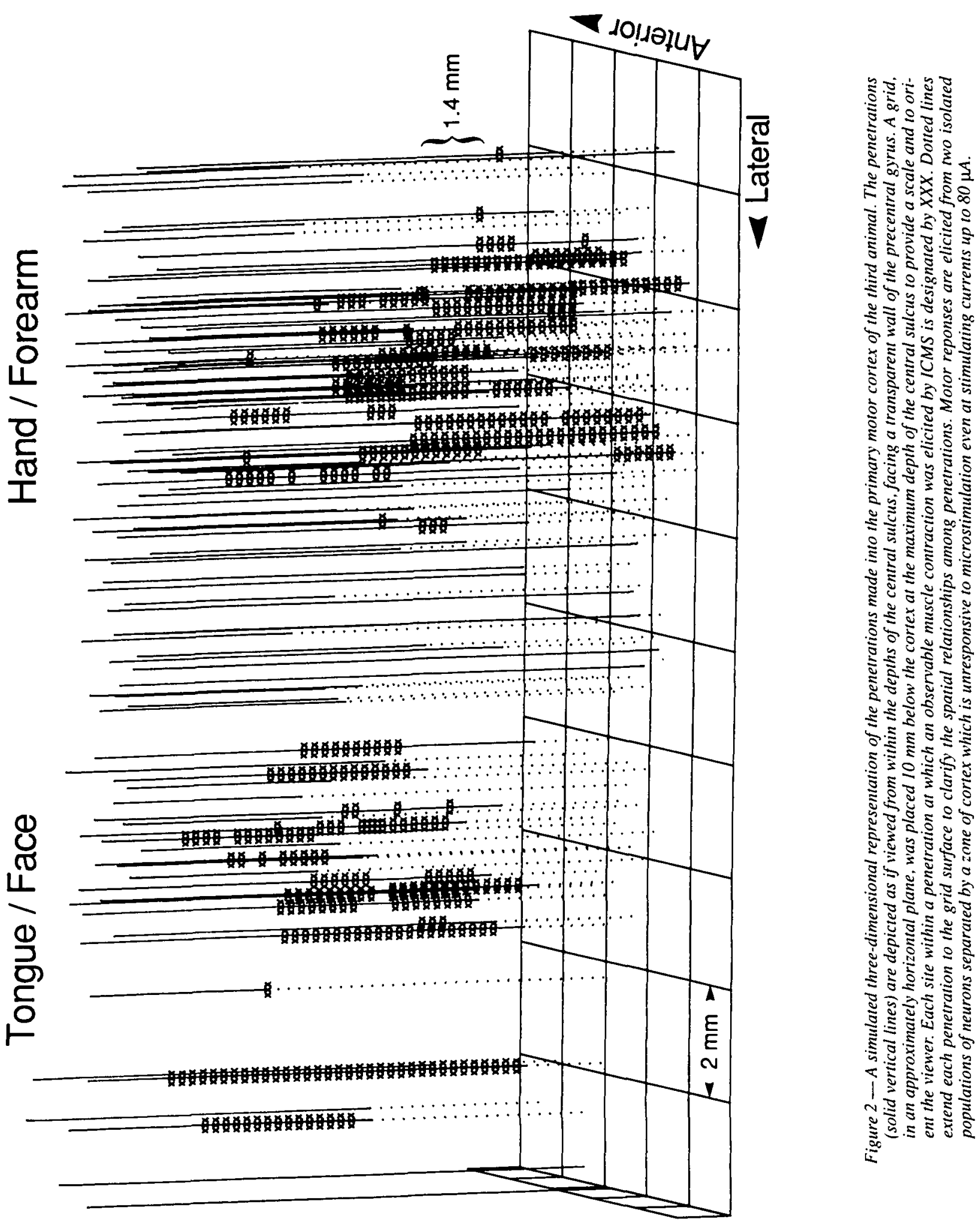
excluded from the data set. The remaining electrode penetrations and their data were displayed in a coordinate system derived from micrometer readings from the micromanipulator. Figure 2 presents these data from the perspective of a viewer standing in the central sulcus looking anteriorly through a transparent precentral gyrus. Locations where ICMS elicited muscle contractions are indicated by XXXs superimposed on the line representing the electrode penetration in which the movement was detected. It is apparent that the representation of the tongue and face and the representation of the hand and forearm lie in two adjacent volumes of cortex separated by a distinct region in which ICMS failed to elicit motor activity. When new electrodes were inserted into regions found to be unresponsive at least several hours earlier in the experiment, the original observations were confirmed and no movements or EMG responses were observed.

\section{Discussion}

This is the first report of motor cortex mapping in the baboon using microstimulation. Heretofore, no unresponsive zone has been reported in the primate motor cortex using ICMS. Our data show that unresponsive zones are consistent and reproducible features of the mototopic order in baboon motor cortex. Several lines of evidence suggest that the unresponsive cortex at the border between the hand and face representations is not an artifact attributable to the microstimulation technique. First, ICMS currents of $30 \mu \mathrm{A}$ were used to search the cortex for muscle contractions. Currents as low as $1-5 \mu \mathrm{A}$ were often sufficient to elicit contractions from face and forelimb musculature in most parts of the area studied. (These low-level currents are similar to the current levels reported by other investigators using lightly anesthetized 5,14 and unanesthetized ${ }^{6-8.13}$ preparations.) Yet, these, and even currents up to $80 \mu \mathrm{A}$, elicited no identifiable muscle contractions in the volume of cortex between the hand and face representation. Second, an unresponsive region occupying approximately the same location was found in the mototopic map of each animal, even though the hand to face transition was encountered at different stages of each experiment. Third, the locations of unresponsive penetrations were confirmed both early and late in an experiment by reinserting a new electrode into a previously mapped location. Fourth, there was no histological evidence of damage to the tissue in the unresponsive region as confirmed at the light microscopic level. Fifth, a similar finding of unresponsive cortex was previously reported by Leyton and Sherrington. ${ }^{19}$ These investigators employed surface electrical stimulation to map the motor cortex in three species of anthropoid apes. They observed a gap in the motor representation between the face and hand representation that was reconfirmed later in the same experiment.

Furthermore, the unresponsive zone cannot be attributed to a failure of our technique of visual observation to detect weak motor unit responses. EMG electrodes were inserted into hand muscles, shoulder muscles and selected muscles in the face, but no EMG responses were detected from stimulation delivered to the unresponsive zone. Thus, it is unlikely that these unresponsive regions produced efferent activity that activated muscles which went undetected by visual observation alone. In addition, we ${ }^{18}$ and others ${ }^{6}$ reported a 1-2 $\mu \mathrm{A}$ difference between the amplitude of current required to evoke a motor unit response and the amplitude of current necessary to evoke a muscle contraction that was visually observed.

One possibility that may account for the presence of the unresponsive zone between the hand-face border is the use of the anesthetized preparation. Our report, however, is not the first study to map the motor cortex in the anesthetized non-human primate; however our finding is the first to report a large consistent region of unresponsive cortex using ICMS. For example, Gould et al 10 used anesthetized owl monkeys to map the complete motor representation, but did not report a gap between the hand-face border. Similarly, McGuinness et al ${ }^{14}$ mapped the face representation in anesthetized macaque monkey; however, they did not report an unresponsive zone at the medial border between the face and forelimb/shoulder representation. While our data cannot entirely rule out the possibility that the unresponsive zone may be highly sensitive to anesthetic level, such a finding would nonetheless be quite provocative.

Also, we cannot rule out the possibility that the unresponsive region elicits contractions of vocal muscles, but an early report by Leyton and Sherrington 19 in apes suggests that such a role is unlikely. They reported that the vocal muscles are represented in a more-lateral part of precentral cortex and not in the region between the face and the hand representation. The possibility that deep muscles may be represented in unresponsive cortex, that in turn do not produce overt movement, remains to be determined.

Asanuma and Arnold 20 have shown that high levels of stimulating currents can transiently inactivate a cortical focus. However, the large expanses of unresponsive cortex, the many test sites, and the fact that the same sites were reexamined at different times with new electrodes suggest that this phenomenon is not due to excessive currents.

The notion of unresponsive zones in primate motor cortex is not a new one. Hines 21 identified a region on the anterior side of the precentral gyrus in monkeys that, when stimulated, caused suppression of motor responses elicited from a more posterior part of area 4. This effect was examined in more detail by Dusser de Barenne and McCulloch, 22 who showed that electrical stimulation or the local application of strychnine to this area suppressed motor movements elicited by periodic electrical stimulation. The effect required several minutes to appear even when elicited by electrical stimuli and lasted for 5 or more minutes. This effect was not an intracortical effect because subcortical projections had to be interrupted to block the phenomenon. These suppressor strips, as they were described, were thought to be part of an extrapyramidal motor control system. The paradigm used in the present study would not have detected the suppressor effects described by Hines ${ }^{21}$ and Dusser de Barenne and $\mathrm{McCulloch}^{22}$ because the stimulation and observation times were too short. Thus it remains to be determined if the unresponsive cortex might be responsible for modulating the excitability of subcortical structures.

The role that an unresponsive region of cortex might play in the organization of the motor cortex is unclear. Our results are nonetheless compelling, especially since this is the first report of a motor map in a baboon, a monkey which has a larger brain size and more highly developed gyral pattern than other monkeys studied. The results may have important implications for understanding the motor organization in man. 


\section{ACKNOWLEDGEMENTS}

This work was funded in part by the Canadian MRC, MA 5522 and MA 10069. D.D.S. was supported by a Quebec FCAR Training Fellowship. R.S.W. was supported by U.S.A. NSF grant BNS 85-16076 and the U.P.F. The authors wish to acknowledge M. Bastien, L. Buyan, C. Chau, N.J. Kabani, S.S. Leclerc, S. McFarlane and I. Salami for their role in the preparation of materials for this paper. We thank $M$. Waters for editing. The computerized graphics were designed and generated by $\mathrm{P}$. Therien.

\section{REFERENCES}

1. Fritsch G, Hitzig E. Uber die elektdrische Erregarkeit des Grosshirns. Arch Anat Physiol Wiss Med 1870; 37: 300-332. (Translation by von Bonin G. In: Nowinski WW, ed. The Cerebral Cortex. Springfield, IL: Thomas 1960; 73-96.)

2. Woolsey CN. Organization of somatic sensory and motor areas of the cerebral cortex. In: Harlow HF, Woolsey CF, eds. Biological and Biochemical Bases of Behavior. Madison: Univ. of Wisconsin Press 1958; 63-81.

3. Asanuma $H$, Sakata $H$. Functional organization of a cortical efferent zone examined with focal depth stimulation in cat. J Neurophysiol 1967; 30: 35-54.

4. Stoney SD Jr, Thompson WD, Asanuma H. Excitation of pyramidal tract cells by intracortical microstimulation: effective extent of stimulating current. J Neurophysiol 1968; 31: 659-669.

5. Asanuma $H$, Rosen I. Topographical organization of cortical efferent zones projecting to distal forelimb muscles in the monkey. Exp Brain Res 1972; 14: 243-256.

6. Huang CS, Sirisko MA, Hiraba $\mathrm{H}$, et al. Organization of the primate face motor cortex as revealed by intracortical microstimulation and electrophysiological identification of afferent inputs and corticobulbar projections. J Neurophysiol 1988; 59: 796818.

7. Kwan HC, MacKay WA, Murphy JT, et al. An intracortical microstimulation study of output organization in precentral cortex of awake primates. J Physiol (Paris) 1978a; 74: 231-233.

8. Kwan HC, MacKay WA, Murphy JT, et al. Spatial organization of precentral cortex in awake primates. II. Motor outputs. J Neurophysiol 1978b; 41: 1120-1131.
9. Kwan HC, Murphy JT, Wong YC. Interaction between neurons in precentral cortical zones controlling different joints. Brain Res 1987; 400: 259-269.

10. Gould HJ III, Cusick CG, Pons TP, et al. The relationship of corpus callosum connections to electrical stimulation maps of motor, supplementary motor, and the frontal eye fields in owl monkeys. J Comp Neurol 1986; 247: 297-325.

11. Neafsey EJ, Bold EL, Sievert CF, et al. The primary motor cortex of the owl monkey: a microstimulation mapping study of the leg and arm areas. Neurosci Abstr 1983; 9: 492.

12. Strick PL, Preston JB. Two representations of the hand in area 4 of primate: I. Motor output organization. J Neurophysiol 1982; 48: 139-149.

13. Sessle $B J$, Wiesendanger $M$. Structural and functional definition of the motor cortex in the monkey (Macaca fascicularis). J Physiol 1982; 323: 245-265.

14. McGuinness E, Sivertsen D, Allman JM. Organization of the face representation in macaque motor cortex. J Comp Neurol 1980; 193: 591-608.

15. Donoghue JP, Wise SP. The motor cortex of the rat: cytoarchitecture and microstimulation mapping. J Comp Neurol 1982; 212: 76-88.

16. Neafsey EJ, Bold EL, Haas G, et al. The organization of the rat motor cortex: a microstimulation mapping study. Brain Res Rev 1986; 11: 77-96.

17. Waters RS, Asanuma H. Low threshold motor output from parietal cortex, areas 5a and 5b, of the cat. Exp Brain Res 1983; 50: 459463.

18. Samulack DD, Waters RS, Dykes RW, et al. Silent zones as a consistent and integral component of the mototopic organization of baboon motor cortex. Soc Neurosci 1987; 13: 241.

19. Leyton ASF, Sherrington CS. Observations on the excitable cortex of the chimpanzee, orang-utan and gorilla. Q J Exp Physiol 1917; 11: 135-222.

20. Asanuma $\mathrm{H}$, Arnold AP. Noxious effects of excessive currents used for intracortical microstimulation. Brain Res 1975; 96: 103-107.

21. Hines M. The "motor" cortex. Bull Johns Hopkins Hosp 1937; 60: 313-336.

22. Dusser de Barenne JG, McCulloch WS. Suppression of motor response obtained from area 4 stimulation of area $4 \mathrm{~s}$.J Neurophysiol 1941; 4: 311-323. 